\title{
Polimorfismo em gene do receptor da progesterona (PROGINS) e da glutationa S-transferase (GST) e risco de câncer da mama: revisão de literatura \\ Gene polymorphisms in the human progesterone receptor gene (PROGINS) and glutathione S-transferase (GST) and risk of breast cancer: a literature review
}

\author{
José Juvenal Linhares', Ismael Dale Cotrim Guerreiro da Silva ${ }^{2}$ Emmanuelle Coelho Noronha ${ }^{3}$, Odair Ferraro ${ }^{4}$, Fausto Farah Baracat ${ }^{5}$
}

\section{Resumo}

A suscetibilidade genética ao câncer da mama compreende dois extremos. Em um, encontram-se as enfermidades monogênicas de elevada penetrância, que são aquelas mutações herdadas dos genes BRCA1 e BRCA2, relacionados aos cânceres hereditários da mama. No outro extremo, encontram-se os polimorfismos, que são mutações muito freqüentes, da ordem de 40 a $50 \%$ da população (como é o caso do polimorfismo nas enzimas da superfamília da glutationa S- transferase da classe GST, presente em 50\% dos caucasianos), com um pequeno aumento do risco individual. Quando falamos de polimorfismos, nos referimos a variações na seqüência do DNA dos genes que codificam determinadas enzimas. Essas variações na seqüência originam proteínas com atividades variáveis e com diferentes capacidades metabólicas, por parte de subgrupos de populaçôes ou por indivíduos isolados. Almeja-se, no presente estudo, mostrar, através de extensa revisão de literatura em periódicos indexados no Lilacs e Medline, onde foram incluídos os principais estudos sobre o assunto, uma visão ampla e global desse tema. Devido ao grande número de polimorfismos, iremos deter-nos a duas classes associadas a maior risco de câncer da mama: PROGINS e GST. São discordantes os dados da literatura, e estudos nacionais são necessários para determinar a real prevalência desses polimorfismos no Brasil e analisar suas correlaçōes com o câncer da mama. Palavras-Chave: Neoplasias mamárias, Polimorfismo genético, Receptores de progesterona e GST.

\footnotetext{
${ }^{1}$ Professor assistente de ginecologia e obstetrícia da Faculdade de Medicina de Sobral - Universidade Federal do Ceará (FAMED-UFC) e ex-médico ginecologista do Hospital do Servidor Público Estadual de São Paulo "Francisco Morato Oliveira" (HSPE - FMO).

${ }_{2}^{2}$ Professor livre docente de ginecologia da UNIFESP e médico encarregado do laboratório de ginecologia molecular da Escola Paulista de Medicina - UNIFESP.

${ }^{3}$ Professora de microbiologia da FAMED-UFC e ex-aprimoranda do laboratório de imunologia e biologia molecular do HSPE - FMO.

${ }^{4}$ Responsável pela seção de mastologia do HSPE - FMO.

${ }^{5}$ Encarregado do setor de oncologia pélvica e patologia mamária do HSPE - FMO.

Realizado pelo serviço de ginecologia e obstetrícia do Hospital do Servidor Público Estadual do Estado de São Paulo "Francisco Morato Oliveira" (HSPE - FMO) e pelo laboratório de ginecologia molecular da Escola Paulista de Medicina - UNIFESP.

Enderę̧o: Rua Cel. Mont'alverne, 1218 - Campo dos Velhos, Sobral - Ceará - CEP: 62011-080. E-mail: juvenallinhares@superig.com.br
} 


\section{Abstract}

Breast cancer genetic susceptibility shows two opposite extremes: 1) monogenetic diseases with high penetration, i.e., the inherited mutations in the BRCA1 and BRCA2 genes related to hereditary breast cancers and 2) polymorphisms, which are highly frequent mutations, including 40 to $50 \%$ of the population (e.g., polymorphism in the glutathione-S enzyme super-family, glutathione-S transferase (GST) class, present in 50\% of Caucasians), with a slightly increased individual risk. Polymorphisms refer to variations in the DNA sequence of genes that code for certain enzymes. Such sequence variations give rise to proteins with variable activity and with different metabolic capacities in population subgroups or single individuals. Based on an extensive review of the Lilacs and Medline databases, where the main studies on this subject were published, the current article aims to provide a comprehensive view of this vast and increasingly important theme. Due to the large number of polymorphisms, the focus was limited to two classes associated with the greatest breast cancer risk: PROGINS and GST. Data in the literature show some disagreement, and national studies are necessary to determine the real prevalence of such polymorphisms in Brazil and to analyze their correlations with breast cancer.

Key words: Breast cancer, PROGINS, GST.

\section{INTRODUÇÃO}

O câncer da mama é o segundo tipo de câncer mais freqüente no mundo e o primeiro entre as mulheres (cerca de um milhão de casos novos estimados). Mais da metade dos casos novos ocorre em países desenvolvidos. A incidência do câncer da mama feminina apresentou um crescimento contínuo na última década, o que pode ser resultado de mudanças sócio-demográficas e acessibilidade aos serviços de saúde. Seu prognóstico é relativamente bom, se diagnosticado nos estádios iniciais. Estima-se que a sobrevida média geral cumulativa após cinco anos seja de $65 \%$ (variando de 53 a $74 \%$ ) nos países desenvolvidos, e de 56\% (49 a 51\%) para os países em desenvolvimento. Na população mundial, a sobrevida média após cinco anos é de $61 \%{ }^{1}$.

Não existem medidas práticas específicas de prevenção primária do câncer da mama aplicável à população, embora estudos observacionais tenham sugerido que a prevenção do tabagismo, alcoolismo, obesidade e sedentarismo reduzam o risco de câncer da mama. Avanços tecnológicos têm sido direcionados para o diagnóstico precoce e o tratamento no sentido de melhorar a sobrevida das pacientes ${ }^{1}$.

Fatores de risco em mulheres incluem história familiar de câncer da mama, diagnóstico confirmado de hiperplasia atípica, densidade da mama aumentada, história de menarca precoce ou menopausa tardia, obesidade após a menopausa, uso de contraceptivos orais ou reposição de hormônios orais (estrogênio e progesterona) pós-menopausa, nuliparidade ou primeira gravidez após 30 anos de idade e consumo de bebidas alcoólicas. Os genes BRCA1 e BRCA2 são responsáveis por cerca de apenas $5 \%$ de todos os casos que ocorrem na população feminina. Por outro lado, a atividade física regular parece ser fator de proteção ${ }^{1}$.

É mais comum em mulheres de classe social elevada e entre aquelas que vivem em grandes cidades. $\mathrm{O}$ número de casos novos de câncer da mama esperados para o Brasil, em 2005, é de 49.470, com um risco estimado de 53 casos a cada 100 mil mulheres. Na região Sudeste, o câncer da mama é o mais incidente entre as mulheres com um risco estimado de 73 casos novos por 100 mil. Sem considerar os tumores de pele não-melanoma, este tipo de câncer também é o mais freqüente nas mulheres das regiôes Sul (71/100.000), Centro-Oeste (38/100.000) e Nordeste (27/100.000). Na região Norte, é o segundo tumor mais incidente $(15 / 100.000)$, sugerindo que fatores como estilo de vida, alimentação e ambientais interfiram na gênese do câncer da mama. ${ }^{1}$

Apesar de ser considerado um câncer relativamente de bom prognóstico, se diagnosticado e tratado oportunamente, as taxas de mortalidade por câncer da mama continuam elevadas no Brasil, muito provavelmente porque a doença ainda seja diagnosticada em estádios avançados. Com base nas informações disponíveis dos Registros Hospitalares do INCA, no período 2000/2001, $50 \%$ dos tumores da mama foram diagnosticados nos estádios III e IV ${ }^{1}$.

Leal et al. (2002) estimam que aproximadamente 10\% das mulheres da população geral dos países ocidentais desenvolverão, em alguma época de sua vida, o câncer da mama. Esta estimativa poderá diminuir em algumas subpopulações, como as das mulheres negras, ou aumentar, como as das mulheres judias de origem askenazi ${ }^{2}$.

Rossini et al. (2002) relataram que uma pequena proporção dos casos de câncer da mama pode ser 
atribuída a razões puramente genéticas, sugerindo a participação associada de outros fatores: dieta, alcoolismo, obesidade e exposição a carcinógenos ${ }^{3}$.

Ruiz et al. (2001) mostraram que as novas tecnologias em genética molecular estão trazendo para esta área de estudo uma verdadeira revolução no conhecimento dos mecanismos etiológicos, como também na conduta terapêutica, abrindo perspectivas para a descoberta de medidas de prevenção no futuro. A principal dessas inovaçóes foi a descoberta de vários sítios de mutação nos genes BRCA1 e BRCA2, e a detecção desses entre afetados e não-afetados de famílias com história de câncer da mamá.

Dentro da oncologia, vem ganhando importância a prevenção como arma principal na redução das taxas de incidência e mortalidade por câncer. As terapias empregadas para o tratamento do câncer somente têm uma modesta efetividade na redução da sua mortalidade. A prevenção é claramente a maior estratégia na redução da mesma. ${ }^{4}$

Ruiz et al. (2001) mostraram que existe um amplo consenso de que a maioria dos cânceres é resultado da exposição a agentes produzidos pelo próprio homem, tais como: agentes externos (tabaco, radiaçôes, contaminantes químicos, alimentos, drogas e agentes infecciosos). $\mathrm{O}$ risco frente a estes carcinógenos está condicionado a fatores genéticos, idade, raça, sexo, reprodutivos, estado imunológico, enfermidades pré-existentes e nutriçãó ${ }^{4}$.

A maioria dos fatores de risco para o câncer da mama está associada à exposição prolongada e elevada de estrogênios. Várias teorias apontam para a ação dos estrogênios através da ativação de fatores de crescimento celular, os quais levariam ao aumento do número de divisões celulares e a maior possibilidade de mutações, contribuindo para a carcinogênese mamária. Outras evidências suportam que metabólitos oxidativos, em particular dos estrogênios, sejam responsáveis pelo processo de iniciação do câncer da mama ${ }^{5}$.

Atualmente, vem se demonstrando, cientificamente, a não homogeneidade da população, o que pode ser verificado em relação a alguns índices de suscetibilidade a uma dada exposição, em que a relação entre o metabolismo dos carcinógenos e o dano genético apresenta variações entre indivíduos de uma mesma população (uma pessoa pode ser muitas vezes mais suscetível ao câncer do que outra). A biologia molecular vem sendo relevante para a avaliação desse risco pessoal, com potencial de constituir uma arma de prevenção e advertência ${ }^{4}$.

Ruiz et al. (2001) estudaram uma classe especial da relação entre a exposição a agentes externos e fatores do hospedeiro representada pelas interações entre os genes e ambiente, na qual incluem-se os polimorfismos genéticos. Quando falamos de polimorfismos, nos referimos a variaçôes na seqüência do DNA dos genes que codificam determinadas enzimas. Essas variaçōes, na sequiência, originam proteínas com atividades variáveis e com diferentes capacidades metabólicas, por parte de subgrupos de populações ou por indivíduos isolados ${ }^{4}$.

A inclusão da análise genética dos polimorfismos na epidemiologia do câncer da mama tem particular interesse, porque permite a identificação de subpopulações de pessoas que são mais suscetíveis ao câncer induzido por determinados agentes químicos. É capaz de estabelecer os limites toleráveis de exposição a determinados agentes e permite o estabelecimento de pautas de seguimento e diagnóstico diferenciado em função dos genótipos de risco ${ }^{4}$.

A suscetibilidade genética ao câncer da mama compreende dois extremos. Em um, encontram-se as enfermidades monogênicas de elevada penetrância, que são aquelas mutações herdadas dos genes BRCA1 e BRCA2, relacionados aos cânceres hereditários da mama. Nestes casos, os riscos acumulados ao longo da vida, entre os portadores das mutações, são muito altos (50$90 \%$ ), porém a prevalência de tais mutações são raras na população geral (2-5\%), o que explica uma pequena fração dos cânceres da mama ser atribuída a caracteres hereditários. No outro extremo, encontram-se os polimorfismos; nestes casos encontramos mutaçōes muito freqüentes, da ordem de 40 a $50 \%$ da população (como é o caso do polimorfismo nas enzimas da superfamília da glutation S-transferase, presente em 50\% dos caucasianos), com um aumento discreto do risco individual. Todavia, o número de cânceres atribuídos a estas características genéticas é muito alto ${ }^{4}$.

Através do estudo da suscetibilidade individual ou de subpopulações, por meio da determinação das freqüências dos polimorfismos que caracterizam diferentes capacidades de metabolização, será possível identificar fatores de risco para muitas doenças e também compreender os mecanismos pelos quais elas se desenvolvem. Essa metodologia poderá auxiliar o indivíduo a optar por um estilo de vida ou tipo e local de trabalho mais saudável e deverá contribuir com a clínica médica na prescrição de drogas ${ }^{6}$.

Para análise dos polimorfismos, primeiro realiza-se a extração do DNA de raspado de mucosa oral ou de células sangüíneas (técnicas mais comumente utilizadas), através de "kits" específicos e padronizados. Em seguida, o estudo do PROGINS e/ou GST, então, é complementado por técnica de ampliação por PCR e leitura em gel de agarose corado com prata ou brometo de etídio.

Mostraremos nesse estudo uma revisão da literatura sobre dois importantes polimorfismos genéticos (PROGINS e GST) e suas correlaçōes com a carcinogênese câncer da mama. 


\section{MATERIAIS E MÉTODOS}

Revisão de literatura em 33 periódicos do Lilacs e Medline, compreendendo o período de 1994 a 2005, onde foram incluídos os principais estudos sobre a correlação do PROGINS e GSTM1 com o câncer da mama.

\section{RESULTADOS E DISCUSSÃO}

\section{POLIMORFISMO FUNCIONAL DO GENE DO RECEPTOR DA PROGESTERONA (PROGINS)}

O receptor da progesterona (RP) faz parte da superfamília dos receptores esteróides derivados do ácido retinóico. O gene para esse receptor encontra-se localizado no cromossomo $11 \mathrm{q} 22-23^{7}$. O RP é um importante regulador do crescimento da glândula mamária e do aparelho reprodutor feminino, e que se encontra envolvido na gênese de tumores malignos. Esse receptor possui duas isoformas. A isoforma "A" capaz de inibir o gene de ativação dos receptores estrogênicos, enquanto a isoforma "B" tem a capacidade de ativá- $-\mathrm{lo}^{8}$.

O PROGINS acontece devido ao processo de inserção gênica, que se deve ao acréscimo de um ou mais nucleotídeos a uma seqüência de DNA. O elemento $A l u$ (elemento de inserção gênica que é adicionado ao material genético devido a erros durante a replicação do DNA) dentro do genoma humano é aquele com maior poder de mobilidade, existindo aproximadamente 1.200.000 cópias desse elemento. Cada repetição do Alu tem aproximadamente 300 nucleotídeos em seu comprimento. A mobilidade do elemento Alu ocorre via processo de retroposição, envolvendo transcrição reversa da RNA polimerase III primária para a forma de cDNA acompanhada da sua intregação ao genoma?.

A inserção do elemento móvel Alu no intron (sequiência de bases que não contribuem para a formação da proteína final) $G$ do RP leva à substituição do $G$ para $\mathrm{T}$ no éxon (região regulatória da expressão gênica), causando a mudança da valina pela leucina no ponto principal do RP e semelhante substituição da citosina pela timina no éxon ${ }^{5}$. A esse complexo polimorfismo genético denominou-se PROGINS?.

As açōes biológicas da progesterona são mediadas por duas isoformas de seu receptor, respectivamente "A" e "B". Em seres humanos, os dois RNA transcritos são gerados a partir de um único gene que tem, porém, regiōes promotoras diferentes. Estruturalmente, as proteínas diferem apenas quanto à presença de 164 aminoácidos na regiāo N-terminal do receptor "B"

A isoforma "A" do RP é a proteína envolvida com o PROGINS, ocorrendo um decréscimo de sua estabilidade com perda da sua capacidade de inibir a ativação dos receptores estrogênicos. Isso pode causar um inadequado controle desses receptores com um aumento do risco de desenvolvimento de tumor ${ }^{7}$. Kieback et al. (1998) acreditam que a isoforma "A" sob ação do polimorfismo levaria também uma maior expressão da isoforma "B", contribuindo para aumento da ação oncogênica do PROGINS10.

Segundo Kieback et al. (1998), a presença do PROGINS na população germânica encontrava-se relacionada com um risco significante de câncer da mama ${ }^{10}$. Em 2003, um estudo sobre polimorfismo funcional do RP verificou acréscimo estatístico no risco de câncer da mama ao estudarem 990 casos, comparados a 1.364 controles $^{11}$. Garret et al. (1995), ao estudarem 187 irlandesas com câncer da mama, constataram uma significativa associação $(\mathrm{p}<0,05)$ do PROGINS com o risco de câncer da mama ${ }^{12}$.

Estudos como os de Lancaster et al. (1998 e 2003) ${ }^{13,14}$, com população caucasiana da Carolina do Norte; Manolistsas et al. (1997), na região do sul da Inglaterra ${ }^{15}$, Pearce et al. $(2005)^{16}$ e Wang-Gohrke et al. $(2000)^{7}$, ao estudarem um grupo de mulheres germânicas com idade inferior a 51 anos, relataram uma relação inversa entre o PROGINS e o risco de câncer da mama. Dunning et al. $(1999)^{17}$, em revisão sistemática de vários artigos da literatura, também não evidenciaram correlação entre esse polimorfismo e o câncer da mama (tabela 1).

Não foram encontrados estudos nacionais que avaliassem a prevalência do PROGINS na população brasileira e nem a correlação deste com o câncer da mama.

\section{POLIMORFISMO DA SUPERFAMÍlIA DA GLUTATIONAS- TRANFERASE (GST)}

As GST fazem parte da superfamília de enzimas envolvidas na fase II de biotransformação, caracterizada pela conjugação de compostos endógenos hidrossolúveis em substratos lipossolúveis. As GST catalisam a conjugação da glutationa, um tripeptídeo composto de glicina, ácido glutâmico e cisteína, em compostos eletrofílicos, resultando numa excreção mais fácil das glutationas conjugadas. Substratos das reações catalisadas pelas GST incluem précarcinógenos, tais como: hidrocarbonos aromáticos policíclicos, drogas farmacológicas, incluindo paracetamol, agentes quimioterápicos e processos decorrentes do estresse oxidativo celular. Recentemente, as GST têm sido implicadas como importantes moléculas envolvidas na ativação de genes citoprotetores. ${ }^{3}$ Outra correlação importante das GST com a mama é a sua capacidade importante de metabolizar por peroxidação estrógenos e lipídios, diminuindo assim a exposição da glândula mamária a esse hormônio ${ }^{18}$.

Os polimorfismos nos genes responsáveis pela 
Tabela 1. Principais estudos mostrando a associação entre o PROGINS e o risco de câncer da mama

\begin{tabular}{|c|c|c|c|c|c|}
\hline \multirow{2}{*}{$\begin{array}{c}\text { Estudo } \\
\text { (No.) }\end{array}$} & \multirow[t]{2}{*}{ Autores } & Casos & Controles & \multirow[t]{2}{*}{ OR } & \multirow[t]{2}{*}{ IC 95\% } \\
\hline & & $\mathrm{N}$ & $N$ & & \\
\hline 01 & De Vivo et al., $2003^{11}$ & 990 & 1364 & 1,33 & $1,01-1,74$ \\
\hline 02 & Garret et al., $1995^{12}$ & 187 & 90 & 1,55 & $0,86-2,82$ \\
\hline 03 & Manolistas et al., $1997^{15}$ & 292 & 220 & 0,77 & $0,50-1,18$ \\
\hline 04 & Lancaster et al., $1998^{13}$ & 68 & 101 & 0,90 & $0,8-2,09$ \\
\hline 05 & Dunning et al., $1999^{17}$ & Metanálise & Metanálise & 0,97 & $0,73-1,28$ \\
\hline 05 & Wang-Gohrke et al., 20007 & 554 & 559 & 0,27 & $0,10-0,4$ \\
\hline 06 & Pearce et al., $2005^{16}$ & 1715 & 2505 & 0,41 & $0,15-0,95$ \\
\hline
\end{tabular}

Odds-ratio foi estimado por modelo de regressão logística , assumindo intervalo de confiança de $95 \%$

produção das GST têm sido bem caracterizados e a sua freqüência encontra-se relacionada a fatores étnicos. Existem três genes principais envolvidos com esses polimorfismos: GSTM1, GSTT1 e GSTP ${ }^{13}$.

O GSTM1 é um gene localizado no cromossomo 1q13.3 . Cerca de 20 a 50\% dos indivíduos o expressam de forma mutada e são conhecidos como deleção gênica homozigótica (acontece quando um ou mais nucleotídeos são eliminados de uma seqüência de DNA) ${ }^{19}$. Foi encontrado por Seidgard et al. (1999), que a porcentagem de indivíduos que não expressam tal gene é mais alta entre os caucasianos e asiáticos do que em africanos ${ }^{20}$.

O GSTT1 está localizado no cromossomo ${ }^{22}$. Entre 20 e $60 \%$ dos indivíduos ocorre o processo de deleção desse gene. É sabido que $60 \%$ dos asiáticos, $40 \%$ dos africanos e $20 \%$ dos caucasianos não expressam a enzima produzida por esse gene ${ }^{21}$.

O GSTP1 está localizado no cromossomo 11q13. Ele é responsável pela produção de uma enzima envolvida na catalisação de reações relacionadas à atividade do epóxido e do dinitrobenzeno ${ }^{21}$.

Um estudo na população brasileira, com 591 voluntários residentes na cidade do Rio de Janeiro, mostrou taxa de polimorfismo de $42,1 \%$ para o GSTM1, 25,4\% para o GSTT1 e 12,2\% para o GSTP13.

Perera et al. (1995) e Cavalieri et al. (1997) sugeriram que os polimorfismos do GSTM1, GSTT1 e GSTP1 têm sido associados com diferentes suscetibilidades a várias formas de câncer, em particular aqueles causados pelos efeitos do tabagismo e participação, também, na gênese do câncer da mama contribuída pelos hidrocarbonetos aromáticos policíclicos (HAP). Nesses mesmos trabalhos, foi encontrada a presença do HAP no DNA de células cancerosas da mama, mas não no
DNA de mulheres sadias ${ }^{22}$ e 23 . Foi evidenciado, por Amorim et al. (2002), em roedores, o aparecimento de tumores da mama, após a exposição prolongada ao HAP. As enzimas da superfamília GST, em especial GSTM1, têm a capacidade de detoxificar os metabólitos reativos do HAP, impedindo assim a sua ligação ao $\mathrm{DNA}^{24}$.

Helzlsouer et al. (1998) sugeriram que o polimorfismo nos membros da superfamília GST estava associado com acréscimo na suscetibilidade ao câncer da mama, principalmente em mulheres na pós-menopausa $(\mathrm{OR}=$ 2,50; IC $95 \%=1,34-4,65)^{25}$. Mitrunen et al. (2002) observaram um aumento no risco de câncer da mama mais acentuado em pacientes na pré-menopausa quando havia uma combinação dos polimorfismos GSTM1, GSTT1 e GSTP1 (OR = 3,96; IC 95\% = 0,99-15,8) ${ }^{26}$. Park et al. (2003) mostraram que a presença desses polimorfismos GSTM1 e GSTT1 aumentam a suscetibilidade ao câncer da mama, principalmente em mulheres na pré-menopausa, com um aumento do risco em 3,1 vezes ${ }^{27}$.

Um estudo nacional, realizado por Amorim et al. (2002), não verificou maior risco de câncer da mama quando presente a deleção nos genes GSTM1 e GSTT1 $(\mathrm{OR}=0,30 ; \text { IC } 95 \%=0,12-0,76)^{24}$.

Millikan et al. (2000) concluíram que os genótipos GSTM1, GSTT1 e GSTP1 não estão associados com maior suscetibilidade ao câncer da mama ${ }^{28}$. Curran et al. (2000), ao estudarem uma população Caucasiana da Austrália de 129 pacientes com câncer da mama, comparadas a 129 controles, não evidenciaram uma maior presença desses polimorfismos em pacientes com a doença, porém não excluíram essa maior presença caso esses polimorfismos apareçam associados numa mesma paciente ${ }^{29}$. Gudmundsdottir et al.(2001) viram 
que o GSTM1 e o GSST1 não mostraram relação com o câncer da mama $(p=0,11)$ e observaram uma tendência, porém não estatisticamente significante ${ }^{30}$.

Em relação ao GSTM1, os maiores estudos como o de Vogl et al. (2004) $)^{31}$ com 2048 pacientes, Egan et al. $(2004)^{32}$ com 1144 pacientes e um estudo de metanálise realizado por Sull et al. $(2004)^{33}$ apontam para uma não correlação entre estes e a etiopatogenia da carcinogênese mamária (tabela 2).

\section{CONCLUSÕES}

São discordantes os dados da literatura, apesar da maioria dos estudos não apontar um aumento no risco para câncer da mama em pacientes com os polimorfismos PROGINS e GST. Estudos nacionais são necessários para determinar a real prevalência desses polimorfismos no Brasil, e analisar se existe ou não essa maior suscetibilidade.

\section{AGRADECIMENTOS:}

À Fundação de Amparo à Pesquisa do Estado de São Paulo (FAPESP), projeto No. 04/0553-9.

\section{REFERÊNCIAS}

1. Instituto Nacional de Câncer; Ministério da Saúde. Estimativa para 2005 da incidência e mortalidade por câncer no Brasil. Rio de Janeiro: INCA; 2006.

2. Leal ST, Santos KRRA, Maia HGS. Características epidemiológicas do câncer de mama no estado da Paraíba. Rev Brás Mastologia. 2002;12 (2):15-22.

3. Rossini A, Rapozo DC, Amorim LM, Macedo JM, Medina R, Neto JF, et al. Frequencies of GSTM1, GSTT1, and GSTP1 polymorphisms in a Brazilian population. Genet Mol Res. 2002 Sep 30;1(3):233-40

4. Ruiz CAJ, Santos MAP. Sistemas de defensa química em el hombre. Prevención em oncologia. Importância clinica del análisis de polimorfismos de susceptibilidad metabólica [citado em 2001 Abr. 8]. Disponível em: www.sedet.es/ sedet/pdf/prevoncologiatxt.pdf.

5. Mitrunen K, Hirvonen A. Molecular epidemiology of sporadic breast cancer. The role of polymorphic genes involved in oestrogen biosynthesis and metabolism. Mutat Res. 2003;544(1):9-41.

6. RossitA, Froes NDTC. Suscetibilidadegenética, biometabolismo e câncer. Rev Soc Bras Cancer. 2000;10:26-31.

7. Wang-Gohrke S, Chang-Claude J, Becher H, Kieback DG, Runnebaum IB. Progesterone receptor gene polymorphism is associated with decreased risk for breast cancer by age 50 . Cancer Res. 2000;60:2348-50.

8. Fabjani G, Tong D, Czerwenka K, Schuster E, Speiser P, Leodolter $S$, et al. Human progesterone receptor gene polymorphism PROGINS and risk for breast cancer in Australian women. Breast Cancer Res Treat. 2002 Mar;72(2):131-7.

9. Donaldson CJ, Crapanzano JP, Watson JC, Levine EA, Batzer MA. PROGINS Alu insertion and human genomic diversity. Mutat Res. 2002;501:137-41.

10. Kieback DG, Tong X, Weigel NL, Agoulnik IU. A genetic

Tabela 2. Principais estudos mostrando a não correlação do GSTM1 e o risco de câncer da mama

\begin{tabular}{|c|c|c|c|c|c|}
\hline \multirow{2}{*}{$\begin{array}{c}\text { Estudo } \\
\text { (No.) }\end{array}$} & \multirow{2}{*}{ Autores } & Casos & Controles & \multirow{2}{*}{ O.R } & \multirow{2}{*}{$95 \% \mathrm{Cl}$} \\
\hline & & $N$ & $N$ & & \\
\hline 01 & Vogl et al., $2004^{31}$ & 2048 & 1969 & 0,98 & $0,86-1,12$ \\
\hline 02 & Sull et al., $2004^{33}$ & Metanálise & Metanálise & 1,06 & $0,99-1,14$ \\
\hline 03 & Helzlsover et al., $1998^{25}$ & 86 & 87 & 0,94 & $0,35-1,54$ \\
\hline 04 & Amorim et al., $2002^{24}$ & 49 & 133 & 0,28 & $0,42-1,00$ \\
\hline 05 & Milikan et al., $2000^{28}$ & 322 & 334 & 0,03 & $0,27-0,34$ \\
\hline 06 & Gudmundsdottir et al., $2001^{30}$ & 500 & 395 & 0,01 & $0,24-0,28$ \\
\hline 07 & Curran et al., $2000^{29}$ & 129 & 129 & 0,03 & $0,46-0,52$ \\
\hline 08 & Egan et al., 2004 32 & 1144 & 1221 & 0,97 & $0,82-1,14$ \\
\hline
\end{tabular}

Odds-ratio foi estimado por modelo de regressão logística , assumindo intervalo de confiança de 95\% 
mutation in progesterone receptor (PROGINS) leads to an increased risk of non-familial breast and ovarian cancer causing inadequte control of estrogen receptor drinen proliferation. J Soc Gynecol Investig. 1998;5(1): supplement $40 \mathrm{~A}$.

11. De Vivo I, Hankinson SE, Colditz GA, Hunter DJ. A Functional Polymorphism in the Progesterone Receptor Gene Is Associated with an Increase in Breast Cancer Risk. Cancer Res. 2003;63:5236-8.

12. Garret E, Rowe SM, Coughlan SJ. Mendelian inhritance of a Taq I restriction fragment lenght polymorphism due to an insertion in the human progesterone receptor gene and its allelic imbalance in breast cancer. Cancer Res Ther Control. 1995;4:217-22.

13. Lancaster JM, Berhuck A, Carney ME, Wiseman R, Taylor JA. Progesterone receptor gene polymorphism and risk for breast and ovarian cancer. Br J Cancer. 1998; 78:227.

14. Lancaster JM, Wenham RM, Halabi S, Calingaert B, Marks JR, Moorman PG, et al. No relationship between ovarian câncer risk and progesterone receptor gene polymorphism in a population-based, case-control study in North Carolina. Cancer Epidemiol Biomarkers Prev. 2003 Mar;12(3):226-7

15. Manolitsas TP, Englefield P, Eccles DM, Campbell IG. No association of a 306-bp insertion polymorphism in the progesterone receptor gene with ovarian and breast cancer. Br J Cancer. 1997;75:1398-9.

16. Pearce CL, Hirschhorn JN, , Wu AH., Burtt NP et al. Clarifying the PROGINS Allele Association in Ovarianand Breast Cancer Risk: A Haplotype-Based Analysis. J Natl Cancer Inst. 2005;97(1):51-9.

17. Dunning AM, Healey CS, Pharoah PD, Teare MD, Ponder BA, Easton DF. A systematic review of genetic polymorphisms and breast cancer risk. Cancer Epidemiol Biomarkers Prev. 1999;8(10):843-54

18. Herrington DM, Howard ID, Hawkins GA, Reboussin DM, Xu J, Zheng SL, et al. Estrogen receptor polymorphism and effects of estrogen replacement on high-density lipoprotein cholesterol in women with coronary disease. New Engl J Med. 2002;364(13):967-74.

19. Pemble S, Schroder KR, Spencer SR. Human glutathione S-transferase theta (GSTT1): cDNA cloning and the characterization pf a genetic polymorphism. Biochem J. 1994;300 (Part 1):271-6.

20. Seidgard J, Vorachek WR, Pero RW, Pearson WR. Hereditary differences in the expression of the human glutathione $S$ transferase activity on trans-stilbene oxide are due to a gene deletion. Proc Natl Acad Sci USA. 1999;85:7293-7.

21. Strange RC, Fryer AA. The glutathione S-transferase: influence of polymorphism on cancer susceptibility. Metabolic Polymorphism and Susceptibility to Cancer.
1999;148:231-49.

22. Perera FP, Estabrook A, Hewer A, Channing K, Rundle A, Mooney LA, et al. Carcinogen-DNA adducts in human breast tissue. Cancer Epidemiol Biomarkers Prev. 1995 AprMay;4(3):233-8.

23. Cavalieri EL, Stack DE, Devanesan PD, Todorovic R, Dwivedy I, Higginbotham S, et al. Molecular origin of cancer: cathecol estrogen-3,4-quinoses as endogenous tumor initiators. Proc Natl Acad Sci U S A. 1997 Sep 30;94(20):10937-42.

24. da Fonte de Amorim L, Rossini A, Mendonca G, Lotsch P, de Almeida Simao T, de Moura Gallo C, et al. CYP1A1, GSTM1, and GSTT1 polymorphisms and breast cancer risk in Brasilian women. Cancer Lett. $2002 \mathrm{Jul}$ 26;181(2):179-86.

25. Helzlsouer KJ, Selmin O, Huang HY, Strickland PT, Hoffman S, Alberg AJ, et al. Association between glutathione S-transferase M1, P1, and, T1 genetic polymorphisms and development of breast cancer. J Natl Cancer Inst. 1998 Apr 1;90(7):512-8.

26. Mitrunen K, Kataja V, Eskelinen M, Kosma VM, Kang D, Benhamou S, et al. Combined COMT and GST genotypes and hormone replacement therapy associate breast cancer risk. Pharmacogenetics. 2002;12(1):67-72.

27. Park SK, Kang D, Noh DY, Lee KM, Kim SU, Choi JY, et al. Reproductive factors, glutathione S-transferase M1 and $\mathrm{T} 1$ genetic polymorphisms and breast cancer risk. Breast Cancer Res Treat. 2003 Mar;78(1):89-96.

28. Milikan R, Pittman G, Tse C, Savitz DA, Newman B, Bell D. Glutathione S-transferase M1, T1, and P1 and breast cancer. Cancer Epidemiol Biomarkers Prev. 2000;9:567-73.

29. Curran JE, Weinstein SR, Griffiths LR. Polymorphisms of glutathione S-transferase genes (GSTM1, GSTP1, and GSTT1) and breast cancer susceptibility. Cancer Lett. 2000;153:113-20.

30. Gudmundsdottir K, Tryggvadottir L, Eyfjord JE. GSTM1, GSTT1, and GSTP1 genotypes in relation to breast cancer. Cancer Epidemiol Biomarkers Prev. 2001;10: 1169-73.

31. Vogl FD, Taioli E, Maugard C, Zheng W, Pinto LF, Ambrosone C, et al. Glutathione S-transferases M1, T1, and P1 and breast cancer: a pooled analysis. Cancer Epidemiol Biomarkers Prev. 2004;13(9):1473-9.

32. Egan KM, Cai Q, Shu XO, Jin F, Zhu TL, Dai Q, et al. Genetic polymorphisms in GSTM1, GSTP1, and GSTT1 and the risk for breast cancer: results from the Shanghai Breast Cancer Study and meta-analysis. Cancer Epidemiol Biomarkers Prev. 2004;13(2):197-204.

33. Sull JW, Ohrr H, Kang DR, Nam CM. Glutathione Stransferase $\mathrm{M} 1$ status and breast cancer risk: a meta-analysis. Yonsei Med J. 2004;45(4):683-9. 